\title{
Ingredients of Huangqi decoction slow biliary fibrosis progression by inhibiting the activation of the transforming growth factor-beta signaling pathway
}

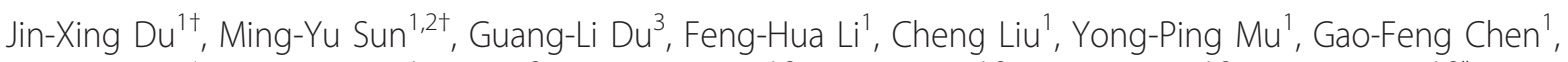

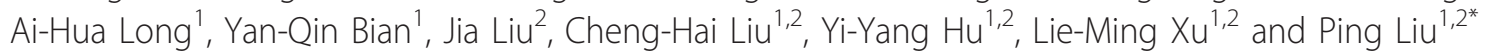

\begin{abstract}
Background: Huangqi decoction was first described in Prescriptions of the Bureau of Taiping People's Welfare Pharmacy in Song Dynasty (AD 1078), and it is an effective recipe that is usually used to treat consumptive disease, anorexia, and chronic liver diseases. Transforming growth factor beta 1 (TGF $\beta 1$ ) plays a key role in the progression of liver fibrosis, and Huangqi decoction and its ingredients (IHQD) markedly ameliorated hepatic fibrotic lesions induced by ligation of the common bile duct (BDL). However, the mechanism of IHQD on hepatic fibrotic lesions is not yet clear. The purpose of the present study is to elucidate the roles of TGF $\beta 1$ activation, Smad-signaling pathway, and extracellular signal-regulated kinase (ERK) in the pathogenesis of biliary fibrosis progression and the antifibrotic mechanism of IHQD.
\end{abstract}

Methods: A liver fibrosis model was induced by ligation of the common bile duct (BDL) in rats. Sham-operation was performed in control rats. The BDL rats were randomly divided into two groups: the BDL group and the IHQD group. IHQD was administrated intragastrically for 4 weeks. At the end of the fifth week after BDL, animals were sacrificed for sampling of blood serum and liver tissue. The effect of IHQD on the TGF $\beta 1$ signaling pathway was evaluated by western blotting and laser confocal microscopy.

Results: Decreased content of hepatic hydroxyproline and improved liver function and histopathology were observed in IHQD rats. Hepatocytes, cholangiocytes, and myofibroblasts in the cholestatic liver injury released TGF $\beta 1$, and activated TGF $\beta 1$ receptors can accelerate liver fibrosis. IHQD markedly inhibited the protein expression of TGF $\beta 1$, TGF $\beta 1$ receptors, Smad3, and p-ERK1/2 expression with no change of Smad7 expression.

Conclusion: IHQD exert significant therapeutic effects on BDL-induced fibrosis in rats through inhibition of the activation of TGF $\beta 1$-Smad3 and TGF $\beta 1$-ERK1/2 signaling pathways.

Keywords: Ingredients of Huangqi decoction, Cholestatic liver fibrosis, Transforming growth factor beta 1, Smadsignaling pathway, Extracellular signal-regulated kinase

\section{Background}

Cholestasis, which was identified as an important factor in a variety of chronic liver diseases [1], results in cholestatic liver fibrosis [2]. The main features of cholestatic liver fibrosis that have been implicated include reduction of hepatocytes, proliferation of cholangiocytes, activation

\footnotetext{
* Correspondence: liuliver@vip.sina.com

+ Contributed equally

Full list of author information is available at the end of the article
}

of myofibroblasts, and deposition of extracellular matrix (ECM) $[3,4]$.

Transforming growth factor beta 1 (TGF $\beta 1$ ) is a member of the TGF $\beta$ superfamily of cytokines, which is known to regulate cell differentiation, proliferation, apoptosis, pro- and anti-inflammatory immune responses, and ECM remodeling [5-7]. Studies have shown that the expression increases of TGF $\beta 1$ and TGF $\beta 1$ type I receptor (T $\beta R I$ ) is one pathological basis for initiation and development of

\section{C) Biomed Central}


immunologically-induced fibrosis in bovine serum albumin (BSA) [8]. TGF 1 1 elevates ECM synthesis by increasing collagen gene transcription in activated hepatic stellate cells (HSCs) [9]. In addition, evidence has indicated that TGF $\beta 1$-mediated bile duct epithelial to mesenchymal transition in hepatic biliary fibrosis [10] and hepatic TGF $\beta 1$ activity reduction could inhibit cholestatic fibrosis induced by bile duct ligation (BDL) [11]. Thus, these studies suggest that TGF $\beta 1$ is an important factor that is involved in the process of cholestatic liver fibrosis.

TGF $\beta 1$ signals through transmembrane Ser-Thr kinase receptors that directly regulate the intracellular Smad pathway [12]. Smads belong to a unique family of signal transduction molecules that can either positively or negatively regulate the transcription of specific genes in response to TGF $\beta 1$ signaling [13]. The TGF $\beta 1 / \mathrm{Smad}$ signaling pathway plays a prominent role in the activation of HSCs and the regulation of the production, degradation, and accumulation of ECM proteins [14].

Extracellular signal-regulated kinase (ERK) is an important member of the mitogen-activated protein kinase (MAPK) family. Recently, the ERK signal pathway has been found to play an important role in regulating ECM synthesis that was stimulated by TGF $\beta 1$ in activated HSCs. Further study has shown that ECM secretion decreased after inhibiting the activation of ERK [15]. Thus, the TGF $\beta 1$ signal transduction pathway has become a new effective target for the prevention and treatment of hepatic fibrosis $[2,16]$.

Limited pharmacological therapy for cholestatic liver fibrosis is available, so new therapeutic approaches are expected. Chinese herbal medicine has recently become a hot topic among practitioners of Western medicine. The principles underlying Chinese herbal medicine were established over thousands of years on the basis of clinical experience and practice, while the effective ingredients in most of these medications have not been identified.

Huangqi decoction, also known as Huangqi Liuyi decoction, was first described in Prescriptions of the Bureau of Taiping People's Welfare Pharmacy in the Song Dynasty (AD 1078). It consists of Radix Astragali, Radix Glycyrrhizae, and Fructus Ziziphi Jujubae. Huangqi decoction has been used for treatment of many conditions, including consumptive disease, restlessness, hydrodipsia, anorexia, and chronic liver diseases. The active ingredients were extracted from Huangqi decoction. We have demonstrated previously [15,17] that Huangqi decoction and its ingredients (IHQD) markedly ameliorated hepatic fibrotic lesions that were induced by BDL. In this study, we elucidated the roles of TGF $\beta 1$ activation, Smad-signaling pathway, and ERK in the pathogenesis of biliary fibrosis progression and the antifibrotic mechanism of IHQD.

\section{Methods}

\section{Reagents and antibodies}

Methanol, acetonitrile, and water for high-performance liquid chromatography (HPLC) were purchased from Merck (Darmstadt, Germany). Prestained protein marker was purchased from New England Biolabs (Beijing, China). Anti-cytokeratin 7 (CK 7) (sc-25721) rabbit antibody was purchased from Santa Cruz and used in 1:50 dilution. Anti-albumin (Alb) (ab8940) sheep antibody, anti- $\alpha$-smooth muscle actin ( $\alpha$-SMA) (ab5694) rabbit antibody, and anti-TGF $\beta 1$ (ab27969) mouse antibody were purchased from Abcam and prepared in 1:200, $1: 200$, and 1:1000 dilution, respectively. Anti-T $\beta$ RI (\#3712) rabbit antibody, anti-T $\beta$ RII (\#3713) rabbit antibody, anti-Smad3 (\#9513) rabbit antibody, anti-p44/42 MAPK (ERK1/2) (\#9107) mouse antibody, and antiphospho p44/42 MAPK (ERK1/2) (\#9106) mouse antibody were purchased from Cell Signaling and diluted 1:1000. Anti-phospho Smad3 (1880-1) rabbit antibody was purchased from Epitomics and used in 1:1000 dilution. Anti-Smad7 (3670-100) rabbit antibody was purchased from BioVision and diluted 1:1000. Secondary fluorescence-labeling goat-anti-mouse $\mathrm{Cy} 3$ and goatanti-rabbit antibody were obtained from Jackson (West Grove, PA, USA) and used in 1:1000 dilution. Labeled rabbit-anti-sheep antibody was obtained from KPL and used in 1:1000 dilution.

\section{Preparation of IHQD}

Huangqi decoction consists of crude herbs in the following dosage: Radix Astragali (30 g), Radix Glycyrrhizae (5 g), and Fructus Ziziphi Jujubae (5 g). The herbal medicines provided by Shanghai Huayu Herbs Co. Ltd. were accredited by a pharmacologist of Shuguang Hospital. The medicinal herb mixture was extracted by boiling water, and the aqueous extracts were vacuum-dried $\left(60^{\circ} \mathrm{C}\right)$ to obtain a powder. The aqueous extracts were further extracted by acetic ether and n-butanol, mixed together, purified by a process using MCI gel column chromatography, eluted with $30 \%$ methanol, and reclaimed as a dry powder.

\section{IHQD fingerprinting by high-performance liquid chromatography (HPLC)}

A, methanol (HPLC grade, Merck, China); B, water; C, methanol (> 99.99\% HPLC grade, Merck, China); seal wash, water/methanol (50/50); needle wash, water/ methanol (50/50).

\section{Sample solution}

One milliliter of the sample was accurately transferred (under content uniformity) into a $50 \mathrm{~mL}$ volumetric flask and a suitable volume of methanol was added. Following this, samples were treated with ultrasonic 
waves for $20 \mathrm{~min}$, placed at room temperature, diluted to volume with $50 \%$ methanol, and mixed well.

\section{Assay}

Five microliters of the sample and standard solution were separately injected into HPLC, the response was recorded (peak area or height), and calculated. First, the column was washed with $100 \%$ methanol with $690-740$ psi system pressure. The mobile phase was methanol with a flow rate of $1.00 \mathrm{~mL} / \mathrm{min}$. Extracted samples were analyzed by HPLC and washed with methanol solution for $30 \mathrm{~min}$ in a gradient manner at a flow rate of $1.0 \mathrm{~mL} / \mathrm{min}$.

The HPLC fingerprints of the IHQD are illustrated in Figure 1.

\section{Animals}

Male Sprague-Dawley rats (180-220 g) were supplied by the Experimental Animal Center to Chinese Academy of Science. The animals were housed in an air-conditioned room at $25^{\circ} \mathrm{C}$ with a $12 \mathrm{~h}$ dark/light cycle. The rats received humane care with unlimited access to chow food and water during the study. All of this study's protocols were approved by Shanghai University of Traditional Chinese Medicine's Animal Ethics Committee.

\section{BDL model of liver fibrosis}

Rats were anesthetized with pentobarbital and BDL was performed as described previously [16]. Briefly, under sodium pentobarbital anesthesia, the common bile duct was double-ligated with 3-0 silk thread after a midline abdominal incision. The common bile duct was exposed and manipulated but not ligated in the sham control group.

\section{Grouping of animals and administration}

The model rats were randomly divided into 3 experimental groups: sham control group $(\mathrm{n}=8)$, BDL alone group $(\mathrm{n}=60)$ and IHQD group $(\mathrm{n}=15)$. The rats in both sham control group and BDL alone group received water administration $(1 \mathrm{~mL}$ per $100 \mathrm{~g})$ for 4 weeks, beginning 1 week after operation. The rats in IHQD group received IHQD orally at a concentration of $17.276 \mathrm{mg}$ per $100 \mathrm{~g}$ body weight every day for 4 weeks, beginning 1 week after BDL operation.

Table 1 The methanol gradient elution of the mobile phase

\begin{tabular}{llll}
\hline Time (min) & A (\%) & B (\%) & C (\%) \\
\hline 0 & 0.5 & 95 & 4.5 \\
15 & 2.5 & 75 & 22.5 \\
35 & 4.5 & 55 & 40.5 \\
45 & 8.0 & 20 & 72 \\
60 & 9.5 & 5.0 & 85.5 \\
\hline
\end{tabular}

\section{Sampling harvesting}

Animals in BDL alone group were sacrificed at the end of $1,2,3,4$, and 5 weeks after BDL $(\mathrm{n}=8-10)$ for dynamic study, and the rats in both sham control group and IHQD group were sacrificed at the fifth weekend after surgery by pentobarbital anesthesia $(50 \mathrm{mg} / \mathrm{kg}$, intraperitoneal injection). Blood samples were obtained from interior vena cava, centrifuged at $3000 \mathrm{r} / \mathrm{min}$ for $30 \mathrm{~min}$ at $4^{\circ} \mathrm{C}$ after $3 \mathrm{~h}$, and serum was kept at $-70^{\circ} \mathrm{C}$ for liver function tests. The livers were rapidly removed, and liver tissue was taken from the right lobe of the liver, fixed in $10 \%$ phosphate-buffered formaldehyde, routinely processed, and blocked into paraffin for detection of collagen content by biochemical methods and image analysis. Some liver tissues were immersed immediately into cyromatrix (TissueTek OCT, Sakura Finetek, Torrance, CA, USA), while other liver tissue was snap-frozen in liquid nitrogen and stored at $-70^{\circ} \mathrm{C}$.

\section{Histological examination \\ Hematoxylin and eosin (H\&E) stain}

Formalin-fixed liver tissues were processed, and $4 \mu \mathrm{m}$ thick paraffin sections were stained with H\&E for 10 min, rinsed with water, and then placed in $75 \% \mathrm{HCl}$-ethanol for $30 \mathrm{~s}$, rinsed with water, placed in eosin-ethanol for 1-2 min, dehydrated, and mounted.

\section{Sirius red stain}

Formalin-fixed liver tissues were processed, and $4 \mu \mathrm{m}$ thick paraffin sections were stained with Sirius red for $60 \mathrm{~min}$, rinsed with $100 \%$ ethanol, dehydrated, and mounted.

\section{Hydroxyproline content in liver tissue and serum biochemistry examination}

Liver tissue $(100 \mathrm{mg}$ ) was prepared for hydroxyproline (Hyp) determination according to a modified method by Jamall et al. [18]. Briefly, liver samples were homogenized and hydrolyzed in $6 \mathrm{~N} \mathrm{HCl}$ at $110^{\circ} \mathrm{C}$ for $18 \mathrm{~h}$. After filtration of the hydrolysate through a $0.45 \mathrm{~mm}$ Millipore filter, chloramine-T was added to a final concentration of $2.5 \mathrm{mM}$. The mixture was then treated with $410 \mathrm{mM}$ paradigm ethyl-amino-benzaldehyde and incubated at $60^{\circ} \mathrm{C}$ for $30 \mathrm{~min}$. After cooling to room temperature, the absorbance of samples was read at $560 \mathrm{~nm}$ against a reagent blank that contained all reagents except tissue. The Hyp content in each sample was determined from a standard and was expressed as micrograms per gram of wet weight $(\mu \mathrm{g} / \mathrm{g})$.

Serum levels of albumin (Alb), alanine aminotransferase (ALT), and total bilirubin (TBil) were measured following the instructions provided by the manufacturer.

\section{Laser confocal microscopy}

Liver samples were immersed into cyromatrix and cut into $5 \mu \mathrm{m}$ thick cryosections. The cryosections were 


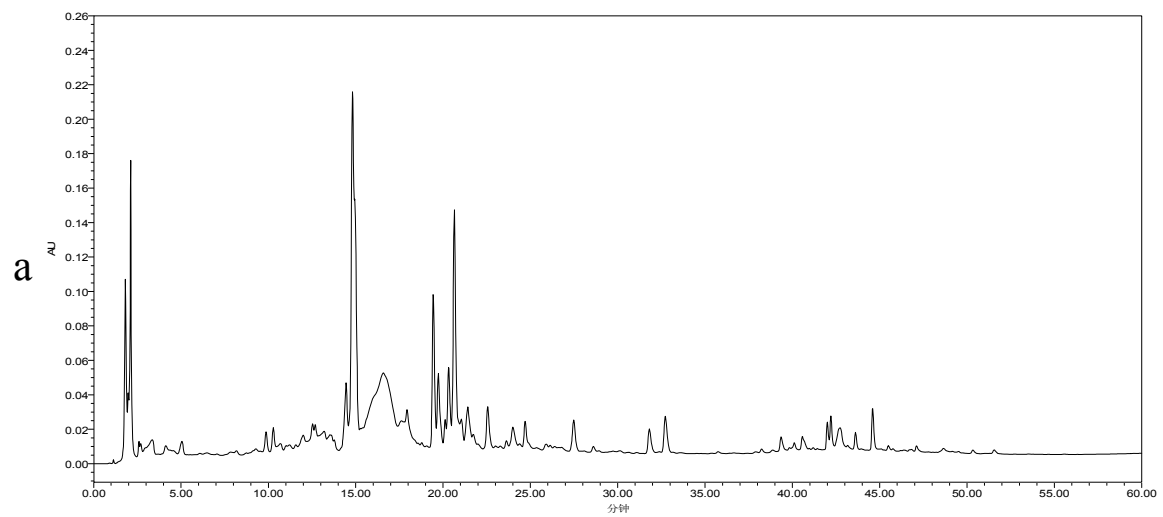

HPLC fingerprinting of Radix Glycyrrhizae

b

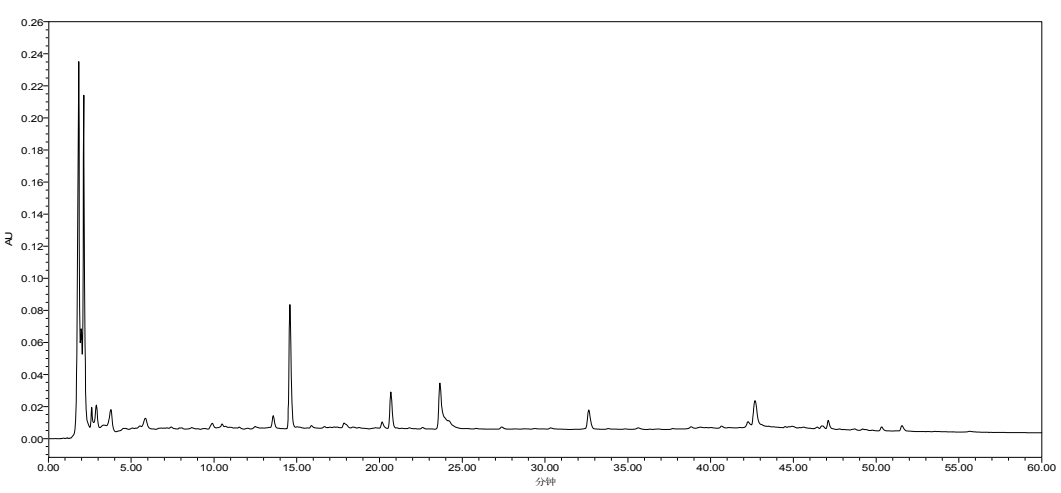

HPLC fingerprinting of Radix Astragali

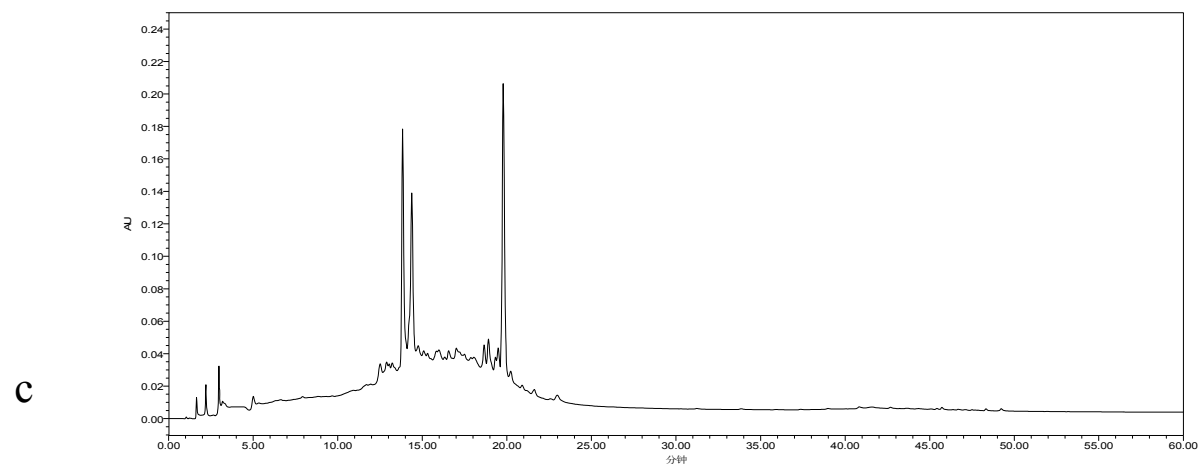

HPLC fingerprinting of Ingridents of Huangqi Decoction

Figure 1 HPLC fingerprinting of IHQD. HPLC fingerprinting of Radix Glycyrrhizae (a), Radix Astragali (b), and ingredients of Huangqi decoction (c).

kept at room temperature for $10 \mathrm{~min}$, placed in $100 \%$ acetone for $10 \mathrm{~min}$, and washed 3 times with PBS. Thereafter, the cryosections were incubated with $5 \%$ bovine serum albumin (BSA) at $37^{\circ} \mathrm{C}$ for $30 \mathrm{~min}$ and incubated with monoclonal anti-TGF $\beta 1$ primary antibody at $37^{\circ} \mathrm{C}$ for $2.5 \mathrm{~h}$. Slides were then washed 3 times with PBS and incubated with the secondary Cy3-conjugated affinipure goat anti-mouse antibody at $37^{\circ} \mathrm{C}$ for 
$1 \mathrm{~h}$. After being washed, the sections were incubated with $\alpha$-SMA, Alb, or CK 7 primary antibody at $37^{\circ} \mathrm{C}$ for $2.5 \mathrm{~h}$, incubated with the secondary goat anti-rabbit, rabbit anti-sheep, or goat anti-rabbit antibody, respectively, at $37^{\circ} \mathrm{C}$ for $1 \mathrm{~h}$, and covered with mounting medium. Imaging analyses were performed using a Leica (Mannheim, Germany) DMIRBE inverted stand and Leica TCS2MP confocal system. A computer-aided morphometric analysis was used to quantitatively determine the positive staining area. Five fields of view were selected randomly from every slice, and the even integration optic density (IOD) value of the positive staining area was corrected by the blank in the same visual field.

\section{Immunoblot analysis}

Liver samples were lysed by RIPA buffer containing $50 \mathrm{mM}$ Tris- $\mathrm{HCl}$ (pH 7.2), $150 \mathrm{mM} \mathrm{NaCl}, 1 \% \mathrm{NP}-40$, $0.1 \%$ SDS, $1 \mathrm{mM}$ EDTA, and $1 \mathrm{mM}$ PMSF and homogenized in ice-water for 3 times for $10 \mathrm{~s}$ at 10,000 rpm. The homogenized solution was transferred to a $1.5 \mathrm{~mL}$ Oak Ridge tube containing 0.1 M PMSF $(0.1 \mathrm{~mL})$, centrifuged for $10 \mathrm{~min}$ at $4^{\circ} \mathrm{C}$ and $12,000 \mathrm{rpm}$ to obtain supernatant. Then, the total protein concentration was determined by Bio-Rad Dc protein Assay Reagent. Proteins were electrophoretically resolved by $10 \%$ SDS polyacrylamide gel and immobilized on Hybond-ECL nitrocellulose membranes. TRIS buffered saline $(20 \mathrm{mM}$ TRIS, $150 \mathrm{mM} \mathrm{NaCl}, \mathrm{pH} 7.4$ ) with $0.1 \%$ Tween-20 and $5 \%$ non-fat dairy milk was used to block non-specific binding sites. Blots were incubated with primary antibodies at $4{ }^{\circ} \mathrm{C}$ overnight and with secondary antibodies at room temperature for $1 \mathrm{~h}$. Bound antibodies were visualized using an enhanced chemiluminescence kit (Pierce, Rockford, IL, USA) and exposed to Kodak BioMax film (Kodak, Rochester, NY, USA).

\section{Statistical analysis}

All data were presented as mean \pm standard deviation. Statistical testing was performed with SPSS software version 12.0. Comparison between groups was performed with test of homogeneity of variances and one-way analysis of variance (ANOVA), and post hoc analysis was performed using Bonferroni or Dunnett's multiple comparison test. Correlation coefficients were calculated by Spearman's rank correlation method. P-values less than 0.05 were considered statistically significant.

\section{Results}

\section{Histological changes}

H\&E stain showed that no morphological abnormality was observed in sham control rats. Persistent reduction of hepatocytes, gradual proliferation of cholangiocytes, and continuous infiltration of neutrophils were noted in $\mathrm{BDL}$ alone rats. Moreover, hepatocytes aggregate to flower cricoids at 2 weeks, and tubular structures were observed at 3, 4, and 5 weeks after BDL. Compared to these observations that were made in rats in BDL alone group, there were obvious improvements in IHQD group (Figure 2a).

Sirius red stain showed that collagen staining was scarcely observed in sham control liver samples except in the area around small central venous walls. In BDL alone rats, extensive peribiliary and interstitial collagen deposits were evident. However, IHQD markedly inhibited hepatic collagen accumulation after BDL (Figure 2b).

\section{Changes in serum liver function and liver tissue Hyp content}

Serum ALT activity, TBil, and liver tissue Hyp content increased gradually, and peaked at the end of the fifth week, while Alb content decreased gradually and reached its lowest level at the end of the fifth week in $\mathrm{BDL}$ alone group compared to values observed in sham control group $(p<0.01)$. Compared to measurements in the 5th week BDL alone group, serum ALT activity, contents of serum TBil, and liver tissue Hyp significantly declined $(p<0.05, p<0.01, p<0.01)$ and serum Alb content remarkably increased in IHQD group $(p<0.05)$ (Table 2).

\section{Changes in protein expression of TGF $\beta 1, \alpha-S M A, A l b$, and CK 7 in liver tissue}

As shown in Figure 3a, the myofibroblast marker $\alpha$-SMA (green) was seen only in the hepatic central vein wall in the portal triads of sham control liver, while TGF $\beta 1$ (red) staining and double staining for both markers (yellow) were light. In BDL alone group, positive staining for $\alpha$ SMA, TGF $\beta 1$, and double staining increased gradually with modeling. $\alpha$-SMA positive staining was predominantly localized in the portal triads at 1,2 , and 3 weeks after BDL. However, strong staining for $\alpha$-SMA was observed around proliferated cholangiocytes at 4 and 5 weeks after BDL. Compared with 5 week BDL alone group, positive staining for $\alpha$-SMA, TGF $\beta 1$, and double staining was significantly decreased in IHQD group $(p<0.01)$.

Strong staining for the hepatocyte marker Alb (green) and faint staining for TGF $\beta 1$ (red) were observed, but positive double staining for both markers (yellow) was completely negative in sham control group (Figure $3 \mathrm{~b}$ ). With progress of modeling, positive staining for Alb decreased gradually; however, positive staining for TGF $\beta 1$ and positive double staining increased gradually. Compared with 5 week BDL alone group, positive staining for Alb increased significantly, but positive staining for TGF $\beta 1$ and positive double staining for them decreased significantly in IHQD group $(p<0.01)$.

As shown in Figure 3c, staining for the cholangiocyte marker CK 7 (green) was completely negative, and 


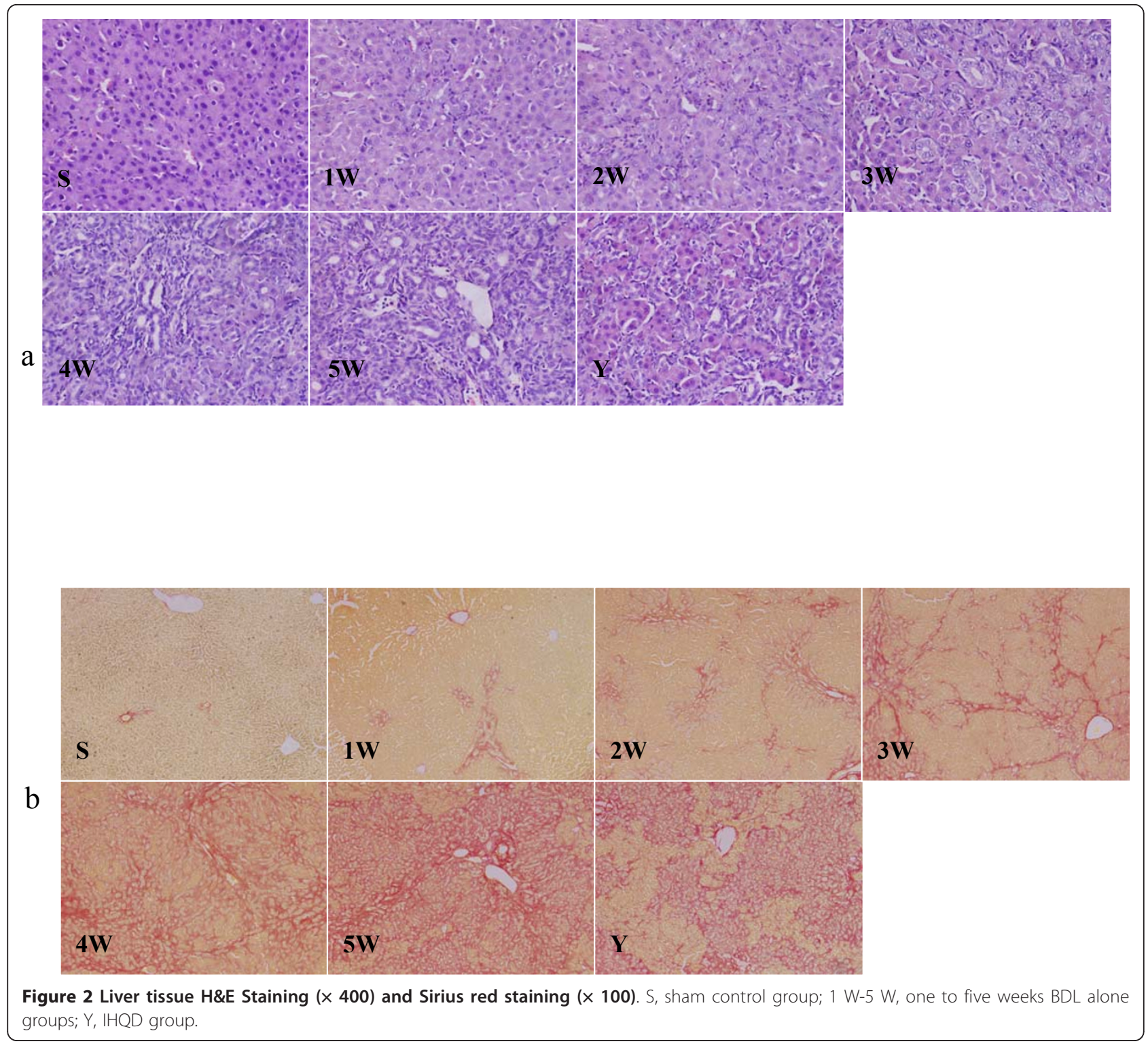

TGF $\beta 1$ staining (red) and double staining for both markers (yellow) were light in sham control group. With progress of modeling, positive staining for CK 7 ,
TGF $\beta 1$, and positive double staining increased gradually, especially at 4 and 5 weeks after BDL. Compared with 5 week BDL alone group, positive staining for CK 7 ,

\section{Table 2 Changes of serum liver function and liver tissue hydroxyproline content in each group (mean S.D.)}

\begin{tabular}{cccccc}
\hline group & $\mathbf{n}$ & TBil(mg/dl) & Alb(g/l) & ALT(u/L) & Hyp ( $\boldsymbol{\mu g} / \mathbf{g}$ wet liver) \\
\hline sham control group & 8 & $0.90 \pm 0.28 \# \#$ & $25.62 \pm 1.98 \# \#$ & $12.92 \pm 1.13 \# \#$ & $164.90 \pm 12.41 \# \#$ \\
\hline 1 week BDL alone group & 8 & $5.24 \pm 0.85^{* * \#}$ & $23.10 \pm 2.45 \# \#$ & $69.18 \pm 2.82^{* * \# \#}$ & $292.96 \pm 93.68^{* * \# \#}$ \\
\hline 2 week BDL alone group & 8 & $5.51 \pm 0.80^{* * \#}$ & $20.97 \pm 0.39^{* * \# \#}$ & $31.68 \pm 4.00^{* * \# \#}$ & $326.93 \pm 14.45^{* * \# \#}$ \\
\hline 3 week BDL alone group & 8 & $5.58 \pm 0.27^{* *}$ & $20.12 \pm 1.57^{* * \# \#}$ & $38.96 \pm 8.15^{* * \# \#}$ & $804.70 \pm 35.50^{* * \# \#}$ \\
\hline 4 week BDL alone group & 8 & $6.16 \pm 0.95^{* *}$ & $16.4 \pm 3.15^{* * \# \#}$ & $56.83 \pm 9.96^{* *}$ & $808.37 \pm 65.93^{* * \# \#}$ \\
\hline 5 week BDL alone group & 10 & $6.72 \pm 0.24^{* *}$ & $12.48 \pm 3.22^{* *}$ & $56.38 \pm 5.79^{* *}$ & $1069.03 \pm 69.27^{* *}$ \\
\hline IHQD group & 14 & $3.08 \pm 0.60^{* * \# \#}$ & $15.18 \pm 2.99^{* * \#}$ & $48.81 \pm 3.57^{* * \#}$ & $853.85 \pm 21.4^{* * \# \#}$ \\
\hline
\end{tabular}

Note: Compared with sham control group, ${ }^{*} p<0.05,{ }^{* *} p<0.01$; compared with 5 week BDL alone group, $\# p<0.05, \# \# p<0.01$. TBil total bilirubin, ALT alanine aminotransferase, Alb albumin, Hyp hydroxyproline 


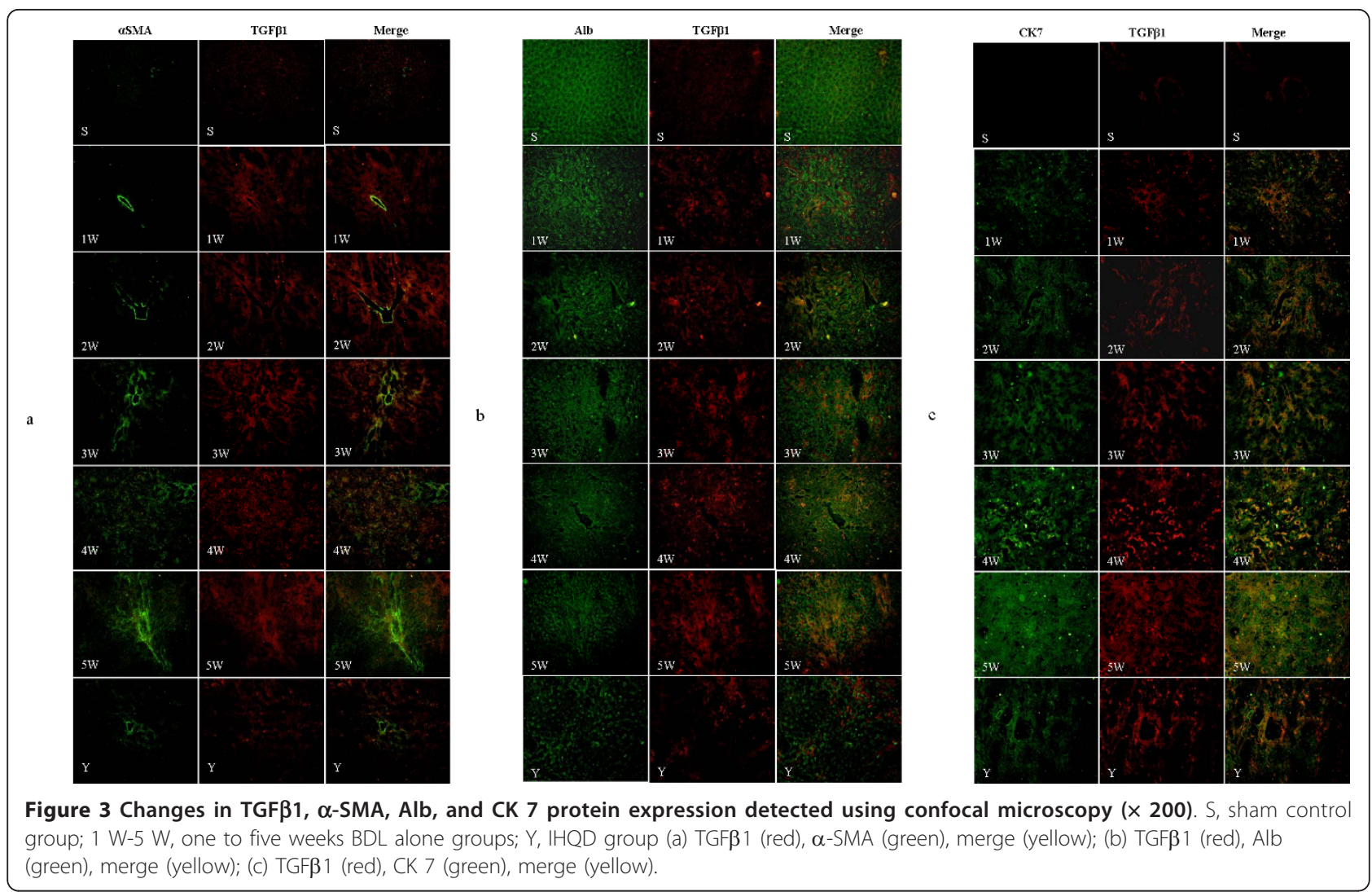

TGF $\beta 1$, and positive double staining was significantly decreased in IHQD group $(p<0.01)$.

\section{Correlation of TGF $\beta 1$ with $\alpha$-SMA, Alb, and CK 7}

The IOD values of TGF $\beta 1, \alpha$-SMA, and CK 7 positive staining areas were calculated (Table 3 ) and the relationships between TGF $\beta 1$ and $\alpha$-SMA, TGF $\beta 1$ and Alb, and TGF $\beta 1$ and CK 7 were analyzed. The IOD value of the TGF $\beta 1$ positive staining area was positively correlated with the level of $\alpha$-SMA $\left(r_{s}=0.8984, p<0.01\right.$, Figure 4a) and CK $7\left(\mathrm{r}_{\mathrm{s}}=0.8572, p<0.01\right.$, Figure $\left.4 \mathrm{c}\right)$, and was negatively correlated with the level of Alb ( $\mathrm{r}=-0.8694, p<$ 0.01 , Figure $4 \mathrm{~b}$ ) in $\mathrm{BDL}$ alone group.

3.5 Changes in the protein expression of $\alpha$-SMA, TGF $\beta 1, T \beta R I, T \beta R I I$, Smad3, phospho-Smad3, Smad7, ERK1/2, and phospho-ERK1/2 in liver tissue

We observed low levels of protein expression of TGF $\beta 1, T \beta R I, T \beta R I I, E R K 1 / 2$, phospho-ERK1/2, and Smad7 in sham control liver tissue, and no obvious protein expression of Smad3, phospho-Smad3, and $\alpha$-SMA. Compared to the protein expression levels in sham control group rats, protein expression of $\alpha$-SMA, T $\beta$ RI, T $\beta$ RII, Smad3, phospho-Smad3, ERK1/2, and phosphoERK1/2 markedly increased with progress of modeling in BDL alone group; these increases were especially evident at 4 and 5 weeks after BDL. However, there were no distinct changes in TGF $\beta 1$ and Smad7 protein expression from 1 to 5 weeks in BDL alone group. The levels of protein expression of all proteins discussed above except Smad7 were significantly decreased in IHQD compared to BDL alone (Figure 5).

\section{Discussion}

BDL is an established animal model of cholestasis with complete biliary obstruction and accumulation of multiple primary bile acids in liver and serum [19]. The changes that are observed in the BDL model of cholestasis parallel those that occur in cholestasis in humans [20]. A previous study has indicated that TGF $\beta 1$ plays a prominent role in stimulating liver fibrogenesis through myofibroblasts that are derived from HSCs [10] during the development of chronic liver injury, including inflammation, fibrosis, and regeneration. In this study, IHQD significantly ameliorated the cholestatic liver fibrosis in BDL rats, and IHQD inhibited the protein expression of TGF 1 .

TGF $\beta 1$, a prototype of multifunctional cytokines, has been proposed to be a "master switch" in the induction of fibrosis [21]. Upregulation of TGF $\beta 1$ expression is a consistent feature of most fibrotic disease [22-24]. Cells, such as HSCs, Kupffer cells, myofibroblasts, endothelial cells, and invading mononuclear cells, could synthesize 
Table 3 The average integration optic density (IOD) values of positive staining areas of $\alpha-S M A, A l b$, CK 7, and TGF $\beta 1$ in liver tissues (mean \pm S.D.)

\begin{tabular}{cccccc}
\hline group & $\mathbf{n}$ & $\boldsymbol{\alpha}$-SMA & Alb & CK 7 & TGF $\mathbf{1}$ \\
\hline sham control group & 8 & $0.02 \pm 0.01 \# \#$ & $0.53 \pm 0.03 \# \#$ & $0.00 \pm 0.00 \# \#$ & $0.03 \pm 0.01 \# \#$ \\
\hline 1 week BDL alone group & 8 & $0.03 \pm 0.01 \# \#$ & $0.34 \pm 0.02^{* * \# \#}$ & $0.06 \pm 0.02^{* * \# \#}$ & $0.07 \pm 0.02^{* \# \#}$ \\
\hline 2 week BDL alone group & 8 & $0.06 \pm 0.01^{* * \# \#}$ & $0.30 \pm 0.02^{* * \# \#}$ & $0.10 \pm 0.02^{* * \# \#}$ & $0.11 \pm 0.03^{* * \# \#}$ \\
\hline 3 week BDL alone group & 8 & $0.14 \pm 0.02^{* * \# \#}$ & $0.24 \pm 0.02^{* * \# \#}$ & $0.16 \pm 0.02^{* * \# \#}$ & $0.15 \pm 0.03^{* * \# \#}$ \\
\hline 4 week BDL alone group & 8 & $0.27 \pm 0.03^{* * \# \#}$ & $0.19 \pm 0.02^{* * \# \#}$ & $0.19 \pm 0.01^{* *}$ & $0.17 \pm 0.02^{* *}$ \\
\hline 5 week BDL alone group & 10 & $0.36 \pm 0.03^{* *}$ & $0.14 \pm 0.02^{* *}$ & $0.21 \pm 0.02^{* *}$ & $0.20 \pm 0.02^{* *}$ \\
\hline HOD group & 14 & $0.11 \pm 0.02^{* * \# \#}$ & $0.28 \pm 0.01^{* * \# \#}$ & $0.15 \pm 0.02^{* * \# \#}$ & $0.15 \pm 0.03^{* * \# \#}$ \\
\hline
\end{tabular}

Note: Compared with sham control group, ${ }^{*} p<0.05,{ }^{* *} p<0.01$; compared with 5 week BDL alone group, \#p $<0.05$, \#\#p $<0.01$. $\alpha$-SMA $\alpha$-smooth muscle actin, Alb albumin, CK 7 cytokeratin 7, TGF $\beta 1$ transforming growth factor $\beta 1$

and release TGF $\beta 1$ [12]. Many studies have created a strong rationale for an antifibrotic strategy in which the principal objective of treatment is blocking TGF $\beta 1$.

Our work suggested that hepatocytes, cholangiocytes, and myofibroblasts could synthesize and release TGF 31 . In return, TGF $\beta 1$ promoted reduction of hepatocytes, proliferation of cholangiocytes, and activation of myofibroblasts (Figures 2, 3, 5). IHQD suppressed TGF $\beta 1$ protein expression and thus suppressed the effects that TGF $\beta 1$ protein expression had on these cell types. These results suggested that TGF $\beta 1$ was a plausible candidate that may play a central role in mediating cholestatic fibrosis, and that suppression of TGF $\beta 1$ expression may be an effective target of IHQD antifibrotic injury.

TGF $\beta 1$ signaling occurs through heteromeric complexes of type I and type II receptors (T $\beta$ RI, T $\beta$ RII) and cytoplasmic protein mediators belonging to the Smad family [25]. The activation of the receptor complexes occurs when T $\beta$ RII transphosphorylates the GS domain of T $\beta R I$. The activated T $\beta R I$ associates transiently with, and also phosphorylates, the receptor-regulated Smads (R-Smads), Smad2 and Smad3. Once phosphorylated, RSmads dissociate from the receptor, bind to Smad4, and enter the nucleus. The activated Smad complex binds to target promoters in association with DNA-binding cofactors, and recruits coactivators to activate transcription. Alternatively, activated Smad complex can also recruit corepressors, which in turn bind histone deacetylases. As a result, Smads can either positively or negatively regulate the transcription of specific genes in response to TGF $\beta 1$ signaling [25-27]. Antagonistic Smad7 competes with RSmads for binding sites to activate T $\beta R I$ and thus prevents the phosphorylation of R-Smads, resulting in receptor degradation [28]. Therefore, Smad7 terminates or reduces the strength of the TGF $\beta 1$-R-Smads signal in a negative feedback loop.

In this study, focusing on the roles of Smad3 and antagonistic Smad7, we investigated the differential regulatory mechanisms of the TGF $\beta 1$ signal in rats during chronic cholestatic liver injury. Our data suggested that in the cholestatic liver injury, hepatocytes, cholangiocytes, and myofibroblasts released TGF $\beta 1$ and activated TGF $\beta 1$ receptors. TGF $\beta 1$ bound its receptor, phosphorylated Smad3, and accelerated liver fibrosis. A remarkable finding noted in other data was that cholestasis induced TGF $\beta$ signaling via Smad3 in vivo [29]. In liver wound healing, Smad3 is required for hepatic stellate cell matrix production and matrix interactions $[9,30]$, as well as maximal type I collagen induction [31]. In addition, highlevel expression of Smad7 protein was also observed. In the process of cholestatic liver fibrosis, Smad7 antagonized Smad3-mediated TGF $\beta 1$ signal in a negative feedback loop without interfering with fibrogenesis. This finding is consistent with previous work [29]. IHQD markedly inhibited the protein expression of Smad3 without changing Smad7 expression, suggesting that IHQD ameliorated cholestatic liver fibrosis by preventing Smad3-mediated TGF $\beta 1$ signal in a positive feedback loop.

Recent findings have suggested a more complex paradigm of TGF $\beta 1$ signaling wherein Smads interact with other signaling cascades, including the MAPK pathway [32]. ERK is an important member of the MAPK family. A study demonstrated that TGF $\beta$ signaling that was activated after BDL was mediated through ERK activation. The decrease of TGF $\beta 1$-induced transcriptional activity by the ERK blockade results from direct suppression of R-Smad dependent transcriptional activation. In addition, differential inhibition of phosphorylation at different Smad serines suggests mechanisms of crosstalk between the Smad and MAPK pathways, which would account for partial inhibition of TGF $\beta$ /Smad signaling by MAPK pathway inhibitors [33]. These results strongly suggest a synergizing role for ERK signal in Smad-signaling that is initiated by TGF $\beta 1$.

In this study, we found that ERK1/2 was activated after BDL, and crosstalk between ERK1/2 and the Smad-signaling pathway enhanced TGF $\beta 1$-dependent responses in cholestatic fibrosis caused by BDL. IHQD inhibited ERK1/ 2 activation after BDL. IHQD may exert its suppressive 

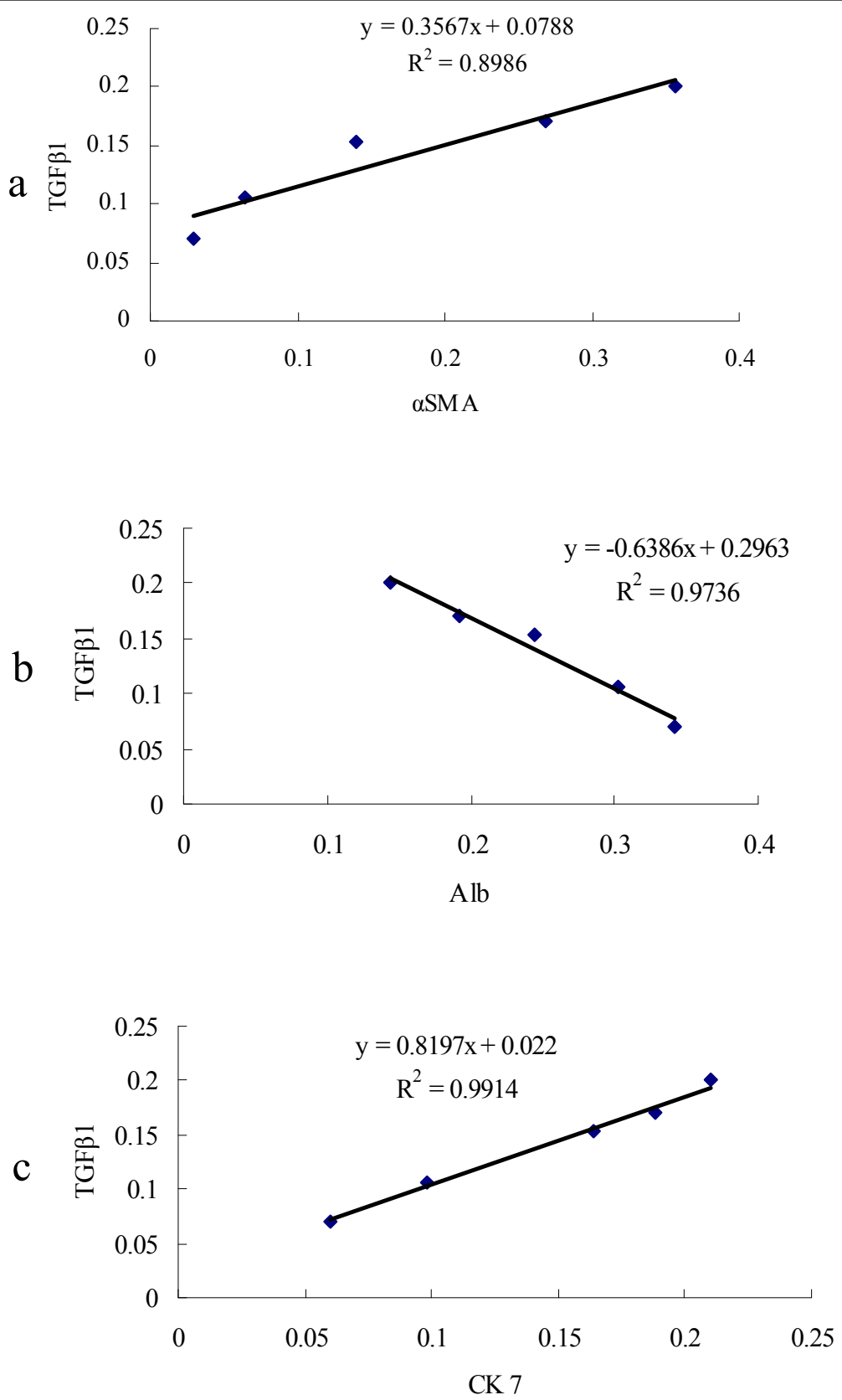

Figure 4 Correlation of positive staining area of TGF $\beta 1$ with $\alpha$-SMA, Alb, and CK 7 protein expression in 1 to 5 weeks BDL alone group. (a) Correlation analysis between TGF $\beta 1$ and $\alpha$-SMA, (b) correlation analysis between TGF $\beta 1$ and Alb, (c) correlation analysis between TGF $\beta 1$ and CK 7.

effects on cholestatic liver fibrosis, at least in part, through suppression of ERK1/2 activation and crosstalk between ERK1/2 and the Smad-signaling pathway.

The multifunctional characteristics of TGF $\beta 1$ indicate a need for tight control of its signaling. Indeed, both positive and negative regulatory mechanisms have been observed at nearly every step in the TGF $\beta 1$ signaling cascade, from release of biologically active ligands to the Smad-mediated transcriptional effects [34]. Our results demonstrated that
TGFß1-mediated induction of Smad3, Smad7, and ERK1/ 2 was involved in this tight regulation of its fibrosis signals in cholestatic liver fibrosis. Smad7 expression increased but did not interfere with fibrogenesis. The TGF $\beta 1$ signal through phosphorylation of Smad3 and activation of ERK1/2 was constantly propagated throughout hepatic biliary injury.

Understanding the differential regulatory mechanisms of the TGF $\beta 1$ signal between physiologic and pathologic 


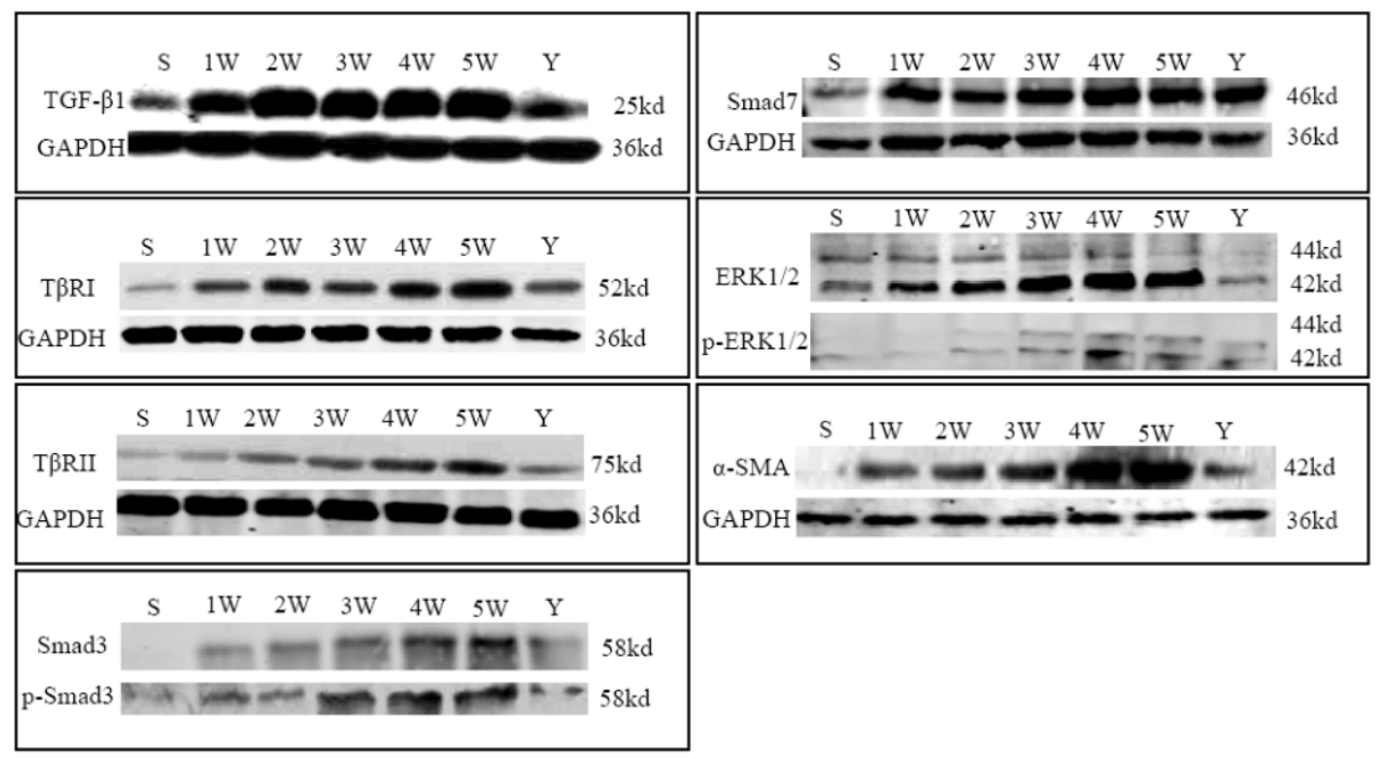

Figure 5 Changes in TGF $\beta 1, T \beta R I, T \beta R I I$, Smad3, phospho-Smad3, ERK1/2, phospho-ERK1/2, Smad7, and $\alpha$-SMA protein expression detected by western blotting. S, sham control group; $1 \mathrm{~W}-5 \mathrm{~W}$, one to five weeks BDL alone groups; Y, IHQD group.

situations will be essential in the design of new therapeutic approaches for various diseases caused by a deregulation of the TGF $\beta 1$ signal. Thus, antagonists of the TGF $\beta 1$ signal could be applied in cholestatic liver fibrosis. Our findings suggested that IHQD suppressed the cholestatic liver fibrosis by inhibiting TGF $\beta 1$ signalmediated activation of Smad3 and ERK1/2. This provides scientific evidence for the clinical application of Huangqi decoction in treatment of cholestatic liver fibrosis.

\section{Conclusions}

Our study indicated that IHQD exerted a significant therapeutic effect on BDL-induced fibrosis in rats by inhibiting the activation of TGF $\beta 1-$ Smad3 and TGF $\beta 1$ ERK1/2 signaling pathways. These findings provide scientific evidence for the clinical application of Huangqi decoction in treatment of cholestatic liver fibrosis.

\footnotetext{
Acknowledgements

This work was supported by National Basic Research Program of China (2006CB504800), National Natural Science Foundation (30672685, 90409020), National S \& T Major Project of China (2009ZX09311-003), Scientific and Technological Project of Shanghai (11DZ1971702), Wang Bao-En Hepatic Fibrosis Research Fund (20100048), E-institute of Shanghai Municipal Education Commission (Project No.E03008), Innovative Research Team in Universities, Shanghai Municipal Education Commission, Shanghai Key Laboratory of Traditional Chinese Clinical Medicine, and Key Disciplines of Liver and Gall Bladder Diseases of State Administration of Traditional Chinese Medicine of the People's Republic of China.
}

\section{Author details}

${ }^{1}$ Key Laboratory of Liver and Kidney Diseases (Ministry of Education), Institute of Liver Diseases, Shuguang Hospital, Shanghai University of
Traditional Chinese Medicine, Shanghai 201203, China. ${ }^{2}$ E-institute of Shanghai Municipal Education Commission, Shanghai 201203, China. ${ }^{3}$ Pharmacy School of Shanghai, University of Traditional Chinese Medicine, Shanghai 201203, China.

\section{Authors' contributions}

JXD and MYS carried out the study and designed the experiments. GLD, $\mathrm{FHL}, \mathrm{CL}, \mathrm{YPM}$, and YQB contributed reagents, materials, and analysis tools. GFC, $A H L$, and $J L$ contributed BDL model. $C H L, Y Y H$, and $L M X$ analyzed data. MYS and GLD supervised work and corrected the manuscript. PL conceived and designed experiments and wrote the manuscript. All authors read and approved the final manuscript.

\section{Competing interests}

The authors declare that they have no competing interests.

Received: 13 October 2011 Accepted: 3 April 2012

Published: 3 April 2012

\section{References}

1. Bedossa $P$, Paradis $\mathrm{V}$ : Liver extracellular matrix in health and disease. $J$ Pathol 2003, 200:504-515

2. Clements WD, Erwin P, McCaigue MD, et al: Conclusive evidence of endotoxaemia in biliary obstruction. Gut 1998, 42:293-299.

3. Dooley S, Hamzavi J, Breitkopf K, et al: Smad7 prevents activation of hepatic stellate cells and liver fibrosis in rats. Gastroenterology 2003, 125:178-191.

4. Du JX, Qiu BF, Liu P, et al: Huangqi decoction inhibits cholangiocyte proliferation and transdifferentiation in cholestatic liver fibrosis induced by BDL in rats. Zhonghua Gan Zang Bing Za Zhi 2010, 18:13-18.

5. Erwin $P$, Bottinger MB: TGF-beta signaling in renal disease. J Am SoC Nephrol 2002, 13:2600-2610.

6. Feng $\mathrm{XH}$, Derynck R: Specificity and versatility in tgf-beta signaling through Smads. Annu Rev Cell Dev Biol 2005, 21:659-693.

7. Franck V, Alain M: Transforming growth factor-beta and fibrosis. World J Gastroenterol 2007, 13:3056-3062.

8. Inagaki $Y$, Mamura $M$, Kanamaru $Y$, et al: Constitutive phosphorylation and nuclear localization of Smad3 are correlated with increased collagen gene transcription in activated hepatic stellate cells. J Cell Physio/ 2001, 187:117-123. 
9. Jamall IS, Finelli VN, Que Hee SS: A simple method to determine nanogram levels of 4-hydroxyproline in biological tissues. Anal Biochem 1981, 112:70-75

10. Xia JL, Dai C, Michalopoulos GK, et al: Hepatocyte growth factor attenuates liver fibrosis induced by bile duct ligation. Am J Pathol 2006, 168:1500-1512.

11. Khimji AK, Shao R, Rockey DC: Divergent transforming growth factor-beta signaling in hepatic stellate cells after liver injury: functional effects on ECE-1 regulation. Am J Pathol 2008, 173:716-727.

12. Liu P, Fang BW, Liu C, et al: The role of transforming growth factor $\beta 1$ and its receptor in immunological induced liver fibrogenesis in rats and effect of cordyceps polysaccharide on them. Zhonghua Gan Zang Bing Za Zhi 1998, 6:232-234.

13. Lutz M, Knaus P: Integration of the TGF-beta pathway into the cellular signalling network. Cell Signal 2002, 14:977-988.

14. Massague J: TGF- $\beta$ signal transduction. Annu Rev Biochem 1998, 67:753-791.

15. Mehra A, Wrana JL: TGF-beta and the Smad signal transduction pathway. Biochem Cell Biol 2002, 80:605-622.

16. Ming DJ, Shu MZ, Hui X, et al: An experimental study of extracellular signal-regulated kinase and its interventional treatments in hepatic fibrosis. Hepatobiliary Pancreat Dis Int 2008, 7:51-57.

17. Qiu BF, Du JX, Shen DZ, et al: Mechanism of hepatocytes transdifferentiation to bile duct epithelial cells and intervention of huangqi decoction. Zhongguo Zhong Xi Yi Jie He Za Zhi 2010, 30:513-518.

18. Schnabl B, Kweon YO, Frederick JP, et al: The role of Smad3 in mediating mouse hepatic stellate cell activation. Hepatology 2001, 34:89-100

19. Seyhan H, Hamzavi J, Wiercinska E, et al: Liver fibrogenesis due to cholestasis is associated with increased Smad7 expression and Smad3 signalng. J Cell Mol Med 2006, 10:922-932

20. Shi LS, Zuo JG, Quan RZ, et al: Effects of Chinese traditional compound, JinSanE, on expression of TGF- $\beta 1$ and TGF- $\beta 1$ type II receptor mRNA, Smad3 and Smad7 on experimental hepatic fibrosis in vivo. World J Gastroenterol 2005, 11:2269-2276.

21. Shi Y, Massague J: Mechanisms of TGF-beta signaling from cell membrane to the nucleus. Cell 2003, 113:685-700.

22. Sime PJ, O' Reilly KM: Fibrosis of the lung and other tissues: new concepts in pathogenesis and treatment. Clin Immunol 2001, 99:308-319.

23. Stedman C, Robertson G, Coulter S, et al: Feed-forward regulation of bile acid detoxification by CYP3A4: studies in humanized transgenic mice. J Biol Chem 2004, 279:11336-11343.

24. Tahashi Y, Matsuzaki K, Date M, et al: Differential regulation of TGF-beta signal in hepatic stellate cells between acute and chronic rat liver injury. Hepatology 2002, 35:49-61.

25. Ten Dijke P, Hill CS: New insights into TGF-beta-Smad signalling. Trends Biochem Sci 2004, 29:265-273.

26. Uemura M, Swenson ES, Gaca MD, et al: Smad2 and Smad3 play different roles in rat hepatic stellate cell function and alpha-smooth muscle actin organization. Mol Bilology Cell 2005, 16:4214-4224.

27. Wahl SM: Transforming growth factor-beta: innately bipolar. Curr Opin Immunol 2007, 19:55-62.

28. Watanabe H, de Caestecker MP, Yamada Y: Transcriptional cross-talk between Smad, ERK1/2, and p38 mitogen-activated protein kinase pathways regulates transforming growth factor-beta-induced aggrecan gene expression in chondrogenic ATDC5 cells. J Biol Chem 2001, 276:14466-14473.

29. Chen WY, Chen CJ, Liao JW, et al: Chromium attenuates hepatic damage in a rat model of chronic cholestasis. Life Sci 2009, 84:606-614.

30. Wrana JL: Regulation of Smad activity. Cell 2000, 100:189-192.

31. Yoshiji H, Kuriyama S, Yoshii J, et al: Angiotensin-II type 1 receptor interaction is a major regulator for liver fibrosis development in rats. Hepatology 2001, 34:745-750.

32. Nishikawa $Y$, Doi $Y$, Watanabe $H$, et al: Transdifferentiation of mature rat hepatocytes into bile duct-like cells in Vitro. Am J Pathol 2005, 166:1077-1088.

33. Zhao J, Shi W, Wang YL, et al: Smad3 deficiency attenuates bleomycininduced pulmonary fibrosis in mice. Am J Physiol Lung Cell Mol Physiol 2002, 282:585-593.

34. Zuo C, Xie C, Deng Y, et al: Effect of Astragalus mongholicus on expression of transforming growth factor-beta1 in SD rats with unilateral ureteral occlusion. Zhongguo Zhong Yao Za Zhi 2009, 34:193-198.

\section{Pre-publication history}

The pre-publication history for this paper can be accessed here: http://www.biomedcentral.com/1472-6882/12/33/prepub

doi:10.1186/1472-6882-12-33

Cite this article as: Du et al.: Ingredients of Huangqi decoction slow biliary fibrosis progression by inhibiting the activation of the transforming growth factor-beta signaling pathway. BMC Complementary and Alternative Medicine 2012 12:33.

\section{Submit your next manuscript to BioMed Central and take full advantage of:}

- Convenient online submission

- Thorough peer review

- No space constraints or color figure charges

- Immediate publication on acceptance

- Inclusion in PubMed, CAS, Scopus and Google Scholar

- Research which is freely available for redistribution

Submit your manuscript at www.biomedcentral.com/submit
Ciomed Central 